\title{
The Heresy of Paraphrase: When the Medium Really Is the Message
} ERNIE LEPORE

Now I may not be an educated man... But it seems to me to go against common sense to ask what the poet is 'trying to say'. The poem isn't a code for something easily understood. The poem is what he is trying to say.

London Fields, Martin Amis

From Aristotle forward, there has been widespread agreement that attempts to paraphrase or translate poetry into literal prose fail in ways that parallel attempts for prose do not. ${ }^{1}$ The New Criticism of Cleanth Brooks, Robert Penn Warren, William Wimsatt and Monroe Beardsley, Murray Krieger, and even of their 'guiding spirit' T.S. Eliot and 'trail blazer' I.A. Richards went so far as to champion the skepticism of the Heresy of Paraphrase as a safeguard for the humanities against the potential charge, by logical positivists, of irrelevance:

The Heresy of Paraphrase: Poetry cannot be paraphrased (or translated).

If this thesis is correct, then some contents are not (re-)expressible in the language of science, since no one denies poems are meaningful. T.S. Eliot, when asked to interpret the line "Lady, three white leopards sat under a juniper tree in the cool of

1. Whether other art forms share this feature with poetry is an interesting question. It is often said that no art form can be fully interpreted, or paraphrased into any other genre, e.g. movies, music, painting, etc. The positive account I'll present below might be able to illuminate these debates as well, even though music, movies, painting, and other art forms are meaningless in the relevant sense I have in mind here.

(C) 2009 Copyright the Authors. Journal compilation () 2009 Wiley Periodicals, Inc. 
the day ...," from his 'conversion poem' Ash Wednesday (1930), responded with, "It means 'Lady, three white leopards sat under a juniper tree in the cool of the day." "The most we can hope to achieve in paraphrasing a poem is repetition.

Philosophers and linguists (with a few notable exceptions) either ignore this skepticism or dismiss out of hand the idea that it is anything special to poetry. Interestingly, pressed with the data, they concede that poetry interpretation and translation must respect more than meaning preservation; it requires attention to form. But this merely restates the skepticism. In what follows, I'll first present data advanced in support of the Heresy of Paraphrase, spell out why many have found it pernicious, and then offer a proposal for how to endorse the thesis without any of its alleged untoward consequences.

\section{THE DATA IN SUPPORT OF THE HERESY OF PARAPHRASE}

The features of poems that coaxed the New Critics into skepticism about paraphrasing poetry include feet, meter, line structure and length, stanzas, form, rhyme, consonance, alliteration, assonance, rhythm, cadence and sundry other poetic devices. These are familiar (traditional and ubiquitous) poetic devices. So, for example, consider the eighth stanza from Keats's poem "The Eve of St. Agnes” (1819):

She danc'd along with vague, regardless eyes,

Anxious her lips, her breathing quick and short:

The hallow'd hour was near at hand: she sighs

Amid the timbrels, and the throng'd resort

Of whisperers in anger, or in sport;

'Mid looks of love, defiance, hate, and scorn,

Hoodwink'd with faery fancy; all amort,

Save to St. Agnes and her lambs unshorn,

And all the bliss to be before to-morrow morn.

Keats's commentators praise its "touches of wild musical beauty" - by which they mean his elaborate technique. Each stanza is Spenserian (a technique invented by Edmund Spenser in the sixteenth century for his Faerie Queene), beginning with eight lines in iambic pentameter and a last in iambic hexameter; and the stanza as a whole has a rhyming pattern of $a b a b b c b c c$. Keats himself was certain that the employing of this technique imposed a unique content on the lines of his poema content that cannot be conveyed with a different meter and rhyming pattern, or even with literal prose.

Even the shape of a presentation on a page has been alleged to impact on the meaning of a poem. Consider E. E. Cummings's poem "Buffalo Bill” (1923):

Buffalo Bill's defunct

who used to

ride a watersmooth-silver

stallion 
and break onetwothreefourfive pigeonsjustlikethat

Jesus

he was a handsome man

and what $\mathrm{i}$ want to know is

how do you like your blueeyed boy

Mister Death

Cummings used typography_he says — to "paint a picture" with his poem. He saw himself as "an author of pictures, a draughtsman of words," exploiting the visual impact of language on paper with unusual line arrangements and punctuation; with the use of the nonstop of the space bar, for example, he evokes a staccato beat to describe Wild Bill Cody's rapid shooting. More dramatic cases abound.

The technique of shaping a poem surfaces as early as Alexandrian Greece in the third century BC with pattern poems composed in the 'bucolic' tradition with verses designed to form a specific shape (such as a pipe, an egg, wings, altar, etc.) with a complimentary theme. In one example, the "Axe," the poem is inscribed upon a votive axe in an unusual line arrangement intended to carry a mystic prophetic message. The tradition continues through to the early seventeenth century with the Welsh poet George Meade, who devised one poem with a visual layout that imitates the shape of butterfly wings and then on to the nineteenth century with Lewis Carroll, who wrote a poem presented in the shape of a mouse tail. These emblematic verses are formatted so as to visually resemble their themes. In the twentieth century the French surrealist Apollinaire and later in the 1950s with Brazilian concrete poets the tradition continued. The current trend towards word art may be a limiting case. (These images raise the question of whether all shapes/forms matter to what the poem says. I believe the answer is 'no'-some do, some don't. How to separate the two is a topic I will return to below.)

In each of these cases of visually shaped poems the claim is that punctuation innovations, typographic style-with words, parts of words, symbols scattered across the page or even with functional objects - the poet can succeed in conveying particularized messages repeatable but-to concur with T.S. Eliot-never paraphrasable.

Most poets look to sound for impact on meaning, given its ancient prewriting history. Critics and translators commonly lament, for example, that the French of Rimbaud is soft, melodious, and fluid in cadence, and since English, and most other, non-Romance languages, certainly Germanic and Slavic languages, encounter severe difficulty in replicating such subtleties, they are unsuitable for translation. And with this loss of sound it is claimed a loss of meaning ensues as well.

Edgar Allan Poe's (1848) poem "The Bells," for example, is a heavily onomatopoeic poem, best known for its repetition of the word 'bells.' It contains four parts, each darker than its predecessor-from "... the jingling and the tinkling" of the bells in Part 1 to the "... moaning and the groaning" in Part 4. Poe's poem has been interpreted in many ways, the most basic of which is simply as a reflection of the sounds bells make, and the emotions they evoke. It's generally acknowledged that the line "From the bells bells bells bells/Bells bells bells!" brings to mind, or 
elicits the clamoring of myriad church bells. Most commentators deny you can convey this in prose without these particular words.

\section{TRANSLATION}

Commentators feel equally skeptical about translating poetry. Invariably in the preface to a translation of poems is a disclaimer about how poetry resists translation; that-as the Mexican poet Octavio Paz once said-"Poetry is what gets transformed" in translation. Ben Jonson speaks of poetic translation as "a poem based on another poem." Almansi and Merry introduce their influential study on translating poetry with this comment:

[to present a poet] to a foreign public is a desperate enterprise, motivated by love, passion and arrogance... Any smuggler of great poetry into another linguistic country knows well this contradictory feeling, as he is encouraged to his task by his proselytizing urge, discouraged by his common sense. (Almansi and Merry 1977)

The scores of English translations over the centuries of Dante's The Divine Comedy, in particular of its most popular section the Inferno, confirm minimally that no two translators agree about what counts as a correct translation.

There is a contemporary tradition in the English speaking world to ignore rhyme and meter and metaphor and simply to provide a literal rendition of a poem's words. But critics declare these translations 'deficient in music.' To read them is to remain totally ignorant, they say, of the 'feel' of a poem such as Dante's. They complain that by ignoring poetic devices, its rendition cannot be a translation, since the sensual effect is lost, and an incredible amount of meaning is contained within the rhyme and meter and metaphor behind these sensual effects. In short, one is no longer reading the original author but rather the translator. ${ }^{2}$

The idea that the concepts and thoughts expressed in one idiom might be ineluctable in another is pervasive. There is a dogma of early Islam, for example, that the Qur'an has a quality ( ${ }^{\prime}$ 'jaz) by which its rhetorical beauty in the Arabic language is "inimitable" (Buhl 1974, 276). For believers, the idea of a translation of the Qur'an into another language would be absurd: On this understanding, then, as Michael Cook notes, "Arabic is not just the original language of the Qur'an, it is the language of the Qur'an" (Cook 2000, 88). In fact, English versions are not titled The Koran but rather The Koran Interpreted, or The Meaning of the Glorious Koran, and so on.

\section{THE IMPORT OF THE HERESY OF PARAPHRASE}

That an (unambiguous) word might mean one thing in a physics article or on a laundry list, and something else in a poem; even across poems its meaning might

2. Some languages, for example Norwegian, even have a special verb for translating figurative speech; equivalent in meaning to the English verb "to rewrite." 
shift, is not easy to embrace. How can word meaning be a function of how a word is presented? Sacrificing the idea that what an (unambiguous) word means, it means everywhere it occurs will not sit well with many philosophers, linguists and cognitive scientists. It requires a loss of semantic innocence-a label inspired by a comment Donald Davidson makes in discussing Frege's treatment of propositional attitude verbs, like 'believes that' or 'says that':

Since Frege, philosophers have become hardened to the idea that content sentences in talk about propositional attitudes may strangely refer to such entities as intensions, propositions, sentences, utterances, and inscriptions ... If we could but recover our pre-Fregean semantic innocence, I think it would be plainly incredible that the words 'the earth moves' uttered after the words 'Galileo said that' mean anything different, or refer to anything else, than is their wont when they come in other environments. (Davidson 1968, 108)

Davidson is criticizing a popular solution to the following puzzle (Frege's puzzle). Given (1) and (2), (3) follows: Nothing could be true of Hesperus but not of Phosporus, since they are identical. But given (1) and (4), (5) does not follow.

1. Hesperus $=$ Phosphorus

2. Hesperus appears in the morning.

3. Phosphorus appears in the morning.

4. The Ancient Greeks thought that Hesperus appeared in the morning.

5. The Ancient Greeks thought that Phosphorus appeared in the morning.

How can we reconcile the truth of (1)-(4) and falsity of (5) with the powerful intuition that since Hesperus and Phosphorus are identical whatever is true of one must be true of the other?

Frege's way out denies 'Hesperus' and 'Phosphorus' are about the same object throughout (1)-(5). He proposed that in (4) and (5) the names pick out not Venus, but rather what these names ordinarily mean. There is no need to provide details in order to draw attention to the fact that his solution requires that what an expression means or picks out is a function of where in a discourse it is located. In (1)-(3), the names pick out the exact same planet, but in (4) and (5), they pick out something else.

The Heresy of Paraphrase and Frege's solution are of a piece, since, according to both, what non-ambiguous, noncontext sensitive words mean and pick out can vary across linguistic contexts. The Heresy of Paraphrase goes further, since it denies words (in context) have synonyms.

Davidson, among others, rejects Frege's solution because it violates semantic innocence; his rejection extends to the Heresy of Paraphrase. Barwise and Perry also insist that natural language semantics be innocent where "an innocent semantics takes the reference of a statement-that aspect of signification that depends on the reference of its parts - to be just that which contributes to the reference of the wholes in which it is embedded" (Barwise and Perry 1981, 406). Their constraint is related to Higginbotham's $(1986,33)$ 'indifference principle,' according to which 
"the value of a constituent does not depend upon what it is embedded in." Except for idioms and the like, the 'meaning' of a complex expression should 'depend on' the meaning of its parts and the 'way' those parts are assembled. Since, according to the Heresy of Paraphrase, what the words of a poem mean is contingent upon where in a poem they occur, it violates semantic innocence (and indifference). But why insist upon innocence? In what follows, we'll discuss four distinct avenues of support.

\section{SUPPORT FOR SEMANTIC INNOCENCE}

\section{Productivity}

It is generally acknowledged that natural languages, including idiolects, lack an obvious upper bound on their number of nonsynonymous expressions. They abound with constructions that generate complex expressions from simpler ones, and ultimately, out of primitives. Grammatical sentences can be formed in English by concatenating two sentences with either the expressions 'and' or 'or.' Other constructions have the same effect: For example, relative clause construction and complementization in constructions like 'believes that' or 'it is possible that' take, inter alia, indicative sentences as grammatical complements to form new sentences. These are but a few of the many devices claimed to render natural languages limitless.

Many theorists conclude that the existence of all these meaningful sentences urge a compositional meaning theory with finitely many specifications of meaning for finitely many primitive expressions, and finitely many rules for composing the meanings of complex expressions out of the meanings of simpler components, down to primitives. In this regard, semantic innocence and compositionality work together. Compositionality, the idea that the meaning of a complex expression is constructed from the meanings of its constituents, is invoked to account for productivity; and compositionality is thought to require semantic innocence. It is no accident that both (1) and (2) occur in (3).

1. John left.

2. Mary stayed.

3. John left and Mary stayed.

Competent speakers exploit the prior ascription of meanings to (1) and (2) in order to ascribe a meaning (3). They know this generally about sentences comprised from other sentences. This presumes semantic innocence.

\section{Systematicity}

More recently, in response to a number of theorists who doubt the open-ended or infinite character of natural language, some philosophers/cognitive scientists/ linguists have pushed the systematicity (instead of the productivity) of natural language in motivating the requirement of semantic innocence and compositionality. Roughly, the systematicity of natural language refers to the fact that any language that can express some proposition $\mathrm{P}$ will also be able to express other 
propositions close in meaning to P: For example, any natural language that can express the proposition that John snores and flounders swim can likewise express the proposition that flounders snore and John swims.

One popular explanation for systematicity requires lexical meanings to be context independent; in particular, that words not change meaning across linguistic contexts; that language be semantically innocent. Compositionality says the meanings of 'John snores' and 'John swims' depend, inter alia, on whatever 'John' means, and because 'John' means the same in the context '... snores' as it does in the context '. . . swims,' if you know what 'John' means in one you thereby know what it means in the other.

Compositionality and semantic innocence (whether motivated by considerations of productivity or systematicity) strongly constrain lexical meaning. As Fodor and Pylyshyn put it, "insofar as a language is systematic a lexical item must make approximately the same contribution to each expression in which it occurs" (1988, 42; cf. the essays in Fodor and Lepore 2001).

\section{Learnability}

Learnability has never been far in the background in our discussion. To deny that word meaning is semantically innocent leaves us without an explanation for how natural languages are 'learnable' (see, e.g., Davidson 1965). Each primitive item in the vocabulary of a language must be learned independently, and learning each requires a finite amount of time. A language with infinitely many primitives would therefore require an infinite amount of time to learn. Since we, as a matter of fact, learn languages (even if it's usually just one for Americans), no learned language can have more than finitely many primitives, but since natural languages have infinitely many nonsynonymous expressions, our understanding of indefinitely many expressions must depend not only on our understanding of their primitive components, but also on how these parts are put together. This is not an independent point, since language learning is tantamount to gaining a productive and systematic capacity for producing and understanding novel utterances. How could language learning proceed without accommodating novelty and systematicity?

In summary: semantic innocence requires that 'embedding' a term or name in a linguistic context does not change its meaning. But the Heresy of Paraphrase implies otherwise: an expression $e$ in poem $\mathrm{P}$ (unless excised from $\mathrm{P}$ ) can't be paraphrased or translated without changing the meaning of P. Since a poem's message is recoverable-no one denies that-properties like productivity, systematicity, and learnability should make us pause before endorsing the Heresy of Paraphrase. But whatever your evaluation of these considerations is, the Heresy of Paraphrase seems vulnerable to a more direct refutation.

\section{The Principle of Expressibility}

According to Searle's Principle of Expressibility, any meaning whatsoever can be given exact expression in language. If this is true, then what stops the following refutation of the Heresy of Paraphrase? 
The Simple Refutation: Suppose expression $e$ is in poem $\mathrm{P}$ means $\mathrm{m}$. Let expression $e^{\prime}$ be synonymous with $e$, whether it occurs in $\mathrm{P}$ or elsewhere.

The Simple Refutation follows directly from Searle's principle. Note that the principle doesn't require that $e^{\prime}$ be an extant expression in the language; nothing prevents introducing $\mathrm{e}^{\prime}$ by fiat to mean whatever $e$ means (Searle 1968; see also Katz 1977). $e^{\prime}$-s absence, then, looks to be at most one of mere omission.

\section{WAYS OF AVOIDING THE SIMPLE REFUTATION}

Since the free variables in our discussion are poetry, translation and paraphrase, the Heresy of Paraphrase might accordingly become more or less tractable contingent on how widely or narrowly we construe these practices.

\section{What's It All About?}

Everyone agrees that paraphrasing a poem requires saying what it is about; and contributors agree that whatever a poem is about-no matter how narrowly construed-exceeds anything determined by semantic content alone. Interpretations of poems are never constrained by dictionary (or literal) meaning alone; historical, sociological, or psychological considerations, inter alii, inevitably come into play. Does this suffice to reconcile the Heresy of Paraphrase with the Simple Refutation?

However wide the net of interpretation is cast, the described procedure for re-expression can be so re-cast as well. Whatever a poem is about-however this is determined-novel linguistic items can be introduced to re-express just this information, regardless of form. In short: commitment to a fact of the matter about a poem having a message suffices for the Simple Refutation to kick in.

\section{Feelings}

Alternatively, we might try to switch topics from paraphrase and translation per se to something, say, about the aesthetic, emotive or imagistic quality poems in order to avoid the Simple Refutation. When translators, poets, and critics complain that the 'feel' (Derek Walcott) or 'music' (Seamus Heaney) or 'tone' or 'voice' or 'beauty' of the poem is lost in paraphrase and translation, their wording suggests something other than meaning is at stake.

This brings to mind Frege's notion of tone or coloring-he writes:

... coloring and shading are not objective, and must be evoked by each hearer or reader according to the hints of the poet or the speaker. With such affinity in human ideas art would certainly be impossible; but it can never be exactly determined how the intentions of the poet are realized. (Frege 1892, 161) 
His key idea is that tone resists translation; Frege inferred that the meaning of an expression alone is what must be preserved under translation. But this isn't what the New Critics have in mind when they speak about poetry resisting translationfor one, every text is rhythmic for the same reason every utterance is. Natural languages possess rhythm. Indeed, ordinary language has all the dimensions poetry does. It has a feel, tone, beauty, a voice, music. It is filled with imagery, simile, and metaphor. While imagery, metaphor, etc. are more typical of, or salient in, poetry than in ordinary language, nonetheless it's there, and so, to be told that in paraphrasing or translating poetry these features are lost is not very interesting. It is neither surprising nor interesting to be told something non-contentful, nonpropositional, and non-interpretive is lost in paraphrase or translation. However, the New Critics clearly have in mind the semantics of poetry, not its aesthetics or the psychology of poetry reading, when these endorse the Heresy of Paraphrase. They insist that what words apply to, what they are true of, which parts of the world satisfy them, are determined by their role inside the poem-and this is what tone does not accomplish. Tone makes no difference to the truth of the thought expressed by a given sentence (Frege 1918, 357), whether inside a poem or elsewhere, when it undergoes translation or paraphrase.

The Simple Refutation, then, is consonant with a contemporary tradition that ignores rhyme, meter, and other poetic effects in translation. The defense is that by focusing on word meaning, a translator retains original meaning, which invariably gets twisted when beat, rhyme, meter, and the like are respected.

New Critics complain that dropping the structural elements of a poem inhibits adequate translation or paraphrase, since if a poem's sensual effect is lost, the integrity of its meaning (as exemplified in rhyme and meter) is compromised as well. Translators of Pushkin into English, e.g., Roman Jakobson and Vladimir Nabokov, complain that the 'magic' of his poems is inevitably lost in translation. They flat out deny that what a poem means or says can be by fiat re-articulated with new or old idioms.

\section{Restriction}

No wiggle room derives, as I've already indicated, from restricting the Heresy of Paraphrase to an extant vocabulary. Very likely, no discourse is guaranteed an adequate translation or paraphrase with such a restriction. Since the Heresy of Paraphrase advocates presume that more difficulty attends to paraphrasing and translating poetry than ordinary prose, we don't help them by imposing any restrictions on the scope of the Heresy of Paraphrase.

So in what follows I will assume an unqualified Heresy of Paraphrase thesis, one that is not delimited by scope of interpretation, by a change of topic from semantics/pragmatics to emotion and aesthetics, or by a restricted vocabulary from which adequate paraphrases and translations are legitimately drawn. So construed the Strong Heresy of Paraphrase reads as follows:

The Strong Heresy of Paraphrase: Substituting into a poem any expression for any of its synonyms-extant or invented-or even a grammatical trans- 
formation of its constituent expressions need not achieve successful translation or paraphrase — no matter how broadly these practices are construed.

In what follows, I will argue that even this strong Heresy of Paraphrase thesis does not require sacrificing innocence. This is a good thing since no matter how strong the Simple Refutation may seem, the data in support of the Strong Heresy of Paraphrase are powerful, so powerful that most of its proponents would not have a second thought about sacrificing innocence. But, again, to sacrifice innocence is to assume that form shapes content and this is pernicious. In what follows, I will argue that by attending to an important distinction between expression and articulation, a distinction that the New Critics and everyone else have ignored, we can curtail their appeal to 'the alchemy of the word.' Its significance to the debate over paraphrase and translation will become apparent below.

\section{LANGUAGE AND ITS ARTICULATION}

Consider a plausible and intuitive scenario where three individuals though equally proficient with English still cannot communicate: One speaks but neither writes nor signs; another signs but neither writes nor speaks; and the third writes but neither speaks nor signs. This (probably actual) state of affairs exposes what a mistake it would be to (fully) identify a language and its expressions with any particular medium utilized in articulating it.

Reflection on this simple scenario reveals that the standard model for communication as encoding thoughts into words and decoding them back into thoughts is deficient. A sincere speaker tries to produce an utterance with the same content as the thought he wishes to express; he chooses his expressions and modes of composition accordingly; a successful interpreter in turn needs to recognize the expressions and phrases involved, and exploits his knowledge of their meanings to figure out the content of the utterance and thereby retrieve the thought it expresses. But since different media can articulate the same linguistic message, and since linguistic expressions are distinct from their vehicles of articulation, individuals equally proficient in a single language might not be able to communicate because they fail to share a common medium of articulation. Communication requires not only a shared language both also a shared competence with a medium of articulation.

Looking ahead, I will exploit the distinction between expressions and their articulations in proposing that poems and metaphors are partly about-in the semantic sense of 'about' - both their articulations and whatever their articulated expressions ordinarily mean. How this maneuver differs from the New Critics' neo-Kantian commitment to form shaping content and how it accounts for that sine qua non poems are alleged to exemplify are topics for below.

On its face, saying a poem is about its own articulation hardly seems an advance over the New Critics. The word 'red'-wherever it occurs-is about a color, not about a font or phonemes. Isn't the claim that a poem is about its articulation a blatant violation of semantic innocence? Why in a poem is a word 
about its own articulation but not everywhere it occurs? The answers to these questions will emerge from a discussion of a Frege-like puzzle about metalinguistic discourse.

\section{META-LINGUISTIC DISCOURSE}

Most informants estimate that (1)-(3) are all true.

1. 'RED' is in upper case.

2. 'red' is the same word as 'RED.'

3. 'red' is not in upper case.

But isn't the identity in sentence (2) incompatible with the truth of both (1) and (3)? If the same word is picked out by 'red' and 'RED,' the subjects of (1) and (3), how could one have a property the other lacks?

A standard rejoinder is that all three can be true together because quotation expressions are context sensitive, and so, (1)-(3) can all be true because the referents of the quotation expressions in (1) and (2), for example, differ. In (2), the quotation expressions pick out words; but in (1) and (3), they pick out something else. But if that were true why, then, is it that if all you knew were that someone uttered (4), you would still feel comfortable indirectly (disquotationally) reporting this utterance with (5)?

4. 'red' is a word.

5. Someone said that 'red' is a word.

Your comfort level makes little sense were quotation expressions context sensitive. Note the difference from ordinary context sensitive expressions, e.g., if all you knew is that someone uttered (6) and (7), you would not feel inclined to report these utterances with (8) and (9):

6. I'm happy.

7. That's a table.

8. Someone said that I'm happy.

9. Someone said that that's a table.

You need to know who the original speaker was and what object was being demonstrated. The need to recover details about the original context of utterance before indirectly disquotationally reporting a use of an expression is a hallmark of context sensitivity; why should it differ for quotation expressions if they are context sensitive?

Contextualism about quotation is much like the New Critics' 'contextualism' about poetry. The New Critics are telling us that the meanings of the words shift across contexts. They mean one thing in a poem, something else elsewhere, including in another poem. Interestingly, the same line of criticism about quotation extends in a natural way to contextualism about poetry.

Recall T.S. Eliot's comment the upshot of which is that to say what a line of poetry says it suffices to repeat it. But if word meaning in a poem is contextually determined, you cannot be guaranteed to say what Eliot says in his poem simply by 
repeating him; much like you obviously cannot report what another says with an utterance of (6) by repeating him.

Other problems abound for a contextualist treatment of quotation.

\section{STRONG DISQUOTATIONALISM}

One feature of quotation that sharply individuates it from every other linguistic device in natural language is its strongly disquotational nature. Ordinary speakers know a priori that (10) is true:

10. “Quine” quotes 'Quine.'

Indeed, all quotations respect the following Strong Disquotational Schema (SDS):

(SDS) "e" alone quotes 'e'

(where 'e' stands for any quotable item whatsoever). It's impossible to quote the name 'Quine' with, for example, "Jason" or any other expression; only "Quine" quotes this name.

It follows straightaway that quotation is context insensitive. Call the first quotation in (10) Q1 and its second Q2. If quotation were context sensitive, on any given occasion, various items could be quoted by Q1 and Q2. Nothing in the semantics would guarantee that whatever Q1 quotes on a given occasion will be related to what Q2 quotes on that occasion; and so there would be innumerable ways to render (10) false. But this will surprise competent speakers. ${ }^{3}$

\section{PROXIMITY}

SDS is related to another deep feature of quotation-namely, the proximity relationship that obtains between a quotation and whatever it quotes. Compare "Quine" and its semantic value, namely, the name 'Quine,' with this name and its semantic value, namely, the great American philosopher of the twentieth century. The former are obviously intimately related in a way the latter are not.

These two features of quotation - the SDS and proximity-are astonishing: We all grew up being told that the relation between an expression and its semantic value is arbitrary. Any expression can be assigned to any meaning. This debate is ancient, taking place centuries before the study of language became a subject for specialists. Nearly 2,400 years ago, Plato in the Cratylus had Socrates discuss the contention that an object's name was not just whatever people agreed to call the thing but resulted from a kind of 'inherent correctness,' which linked the object's nature to the speech-sounds used to name it. Plato's idea is universally dismissed as ridiculous. But it's not, at least not for quotation! If the linguistic expression

3. The weight you should put on this intuition will of course depend, in large part, on your view of context sensitivity and how transparent you should expect the phenomenon to be for speakers. I am highly skeptical of views that postulate surprising context sensitivity (cf. Cappelen and Lepore 2004, 12-113; see also Cappelen and Lepore 2007) — the claim that there can be a false utterance of (10) is one of those. 
“Quine” picked out anything other than 'Quine,' it would cease to be a quotation. It is different for all other types of expression.

The predicate 'is red' might have been true of blue things and yet still be a predicate; the name 'Quine' might have picked out Kant and yet still be a name. Even the connective 'and' might have signified disjunction and yet still be a connective. But the quotation expression "Quine" could not have picked out anything other than 'Quine' and still remain a quotation expression. Of course, it might have been a name. We could have opted to name an expression-say my name 'Ernie' with the expression "Quine"-but then those marks flanking the name 'Quine' would no longer be functioning as quotation marks, but rather primitive parts of a name.

These two features of quotation-SDS and proximity-point to a noncontextualist solution to the puzzle surrounding (1)-(3).

\section{BACK TO WORDS AND THEIR ARTICULATIONS}

In discussing (1)-(3), everyone who has ever written on quotation assumes that (1) and (2) (and also (2) and (3)) share at least one quotation expression. The first and last expressions of (1) and (2) respectively are supposed to be the same expression; and the last and first expressions of (2) and (3) respectively are as well. However, in order to respect SDS we must relinquish this assumption. How this is possible is the topic for the next few sections. First I'll show why we need to reject it; and then I'll show why no one has seen this before.

It should be obvious that we can name, describe, demonstrate, and quantify over expressions and their articulations: But we can also quote both. Expressions are commonly quoted, as in (4).

4. 'red' is an English word.

But vehicles are also quotable, as in (11) (and in (1) and (3)).

11. 'red' is one word in English, another in Norwegian; and none in Italian.

It is common for linguists to speak of two languages sharing a word-though its meaning might not be the same in each language. They also speak of the pronunciation of a single word in a single language shifting across time. They say of a single string that it is ambiguous, as in 'Flying planes can be dangers.' The distinction between expressions and their articulations affords us another way to describe the relevant data.

We can speak of the same sound or shape being used to articulate different words in different languages.

We can say of a single vehicle of articulation_-namely, 'Flying planes can be dangerous' - that it corresponds to two different English sentences (where sentences are individuated by their constituents and constituent structure).

Returning to (11), it says that a single vehicle articulates different words (in two different languages); and none in a third. Its truth requires this.

None of this is news to a contextualist about quotation; but since quotation is not context sensitive, it follows that: 
If a quotation expression quotes an expression, it cannot be quoting a vehicle, and if it quotes a vehicle, it cannot be quoting an expression.

Accordingly, (12)-(13) — and here's a significant result—can both correspond to true English sentences!

12. 'red' is a vehicle and not an expression.

13. 'red' is an expression and not a vehicle.

They need not contradict each other (despite appearances) because they need not share a common grammatical subject. Looking back at SDS: According to it, quotation expressions contain as constituents whatever quotable items they quote. This sense of 'containment' is no less innocent than when we say of a single sentence that it contains any number of expressions, as in the sentence 'My brother left' contains three words. But:

If a quotation expression contains whatever it quotes as a constituent, then if it quotes a vehicle, that vehicle must be a constituent of the quotation; and if it quotes an expression, then that expression must be a constituent of the quotation.

In short: because our linguistic practice of quotation respects SDS, the following individuation criterion for quotation expressions obtains:

Quotation Individuation: Quotation expressions are distinct just in case they disagree in semantic value.

Sentences (1)-(3) are all true because their various constituent quotations are all distinct linguistic expressions picking out distinct quotable items.

\section{WHY HAVE WE FAILED TO RECOGNIZE THIS?}

How could it be that everyone failed to recognize that (1)-(3) have distinct grammatical subjects? Why have we all been seduced into falsely thinking that the objects (4) and (11) are about are the same? The reason is because an interpreter who confronts a quotation expression must clear various hurdles in order to identify it, and failure to do so properly easily leads to misidentification.

\section{FROM TOKENS TO VEHICLES}

Interpretation begins with a physical token-a sound or a scribble or a projection on a screen or a hand gesture, and so on. The interpreter's first task is to figure out which vehicle of articulation, if any, does this physical token present. This problem does not admit of an easy solution.

On the one hand, distinct vehicles might be physically indistinguishable. A vehicle is the vehicle it is not solely because of its intrinsic physical properties, but also because of its function inside the entire system of articulation. The physical 
type 'a' might exist in several alphabets but from this we cannot infer it is the same vehicle that resides in both alphabets (even though physically indistinguishable).

On the other hand, physically distinguishable items might still present the same vehicle. Suppose two speakers send emails to each other using figures of different font sizes. These physical differences might not matter for the purposes of exchange and so may not suffice for distinguishing vehicles. In this regard, an ' $a$ ' and an 'a' may present the same vehicle-though physically distinct.

None of this should be surprising; no two of us write in exactly the same manner-our handwritings are distinguishable. People make a career out of being able to pin a person to a scrawl. (And of course the same applies to pronunciations. Actors put a great effort into mimicking regionally displaced speakers of the same language.) Yet no one wants to infer that physically distinguishable handwritings automatically indicate distinct vehicles of articulation. In short: Physical differences among articulations need not indicate differences in articulation; and nonphysical differences needn't indicate identical articulations.

\section{FROM VEHICLES TO EXPRESSIONS}

After getting over the hurdle of vehicular identification, a speaker must still ascertain which linguistic item a presented vehicle articulates. In the case of quotation, this is particularly tricky since the very vehicle doing the articulation may itself be the item quoted by the quotation expression that it articulates; or the vehicle may, instead, articulate a quotation expression that quotes a linguistic expression.

Consider (14) (from Manuel Garcia-Carpintero):

14. 'Madrid' = 'Madrid.'

Contextualists describe (14) as presenting a single context-sensitive English sentence true in some contexts, false in others. This is a mistake. (14) presents a physical type that corresponds to many vehicles which in turn correspond to different sentences, and so, by itself (14) underdetermines which sentence is articulated-one of the sentences it presents corresponds to a trivially true identity between the same quotation expression, and another to an obviously false identity between distinct quotation expressions. To determine which, the interpreter must first determine whether the distinct symbols flanking the identity sign are the same vehicle and then, if so, which linguistic expression(s) these vehicles articulate.

Having identified the vehicles used in articulating quotations in (14) still doesn't determine which expressions these vehicles articulate. The same vehicle can articulate distinct expressions on distinct occasions. The vehicle 'bank' articulates the word 'bank' meaning financial institution on some occasions and another word 'bank' meaning river side on other occasions. These are different words corresponding to the same articulation. That happens.

In the case of (14), this means that the vehicles might articulate distinct quotation expressions; one vehicle might articulate a quotation expression that contains a vehicle as its constituent, and the other vehicle might articulate a quo- 
tation expression that contains an expression as its constituent, say, the name for the capital of Spain. For articulations of quotation expressions, if the quotation expressions the vehicles articulate differ in semantic values, it follows that these quotation expressions themselves are distinct-despite having been articulated by the same vehicle. This is because their constituents-i.e. their semantic values-are distinct. Even after having identified the vehicles employed on an occasion, then, we still need to determine which linguistic expressions these vehicles articulate. This extra work affords yet another opportunity for failure.

Does (14), then, correspond to a true or a false sentence? Before we can answer, we must first decide which sentence a token of (14) is presenting on a given occasion. That an italicized vehicle presents the quotation expression on its right hand side need not be relevant to which expression it is. It might be the expression that makes (15) true or it might be one that makes (16) true.

15. 'Madrid' is the capital of Spain.

16. 'Madrid' is italicized.

Though obviously distinct, the physical data are compatible with the vehicle on the right hand side of (14) articulating either a linguistic expression that quotes a name or one that quotes a vehicle. Contingent on which it is, (14) might be either one of two distinct sentences.

\section{QUOTATION ACROSS SYSTEMS OF ARTICULATION}

Once the difference between expressions and their articulations is acknowledged, the confusions surrounding (1)-(3) become transparent. The difference explains how the mute and the blind and the illiterate can all be competent in the same language. Normally, a linguistic expression is articulable by different vehicles. We can speak, write, sign, Braille or even semaphore the same expression. And of course we can articulate the quotation of a word in each of these distinct systems of articulation. But:

When a quotation expression quotes a vehicle, then only that vehicle can be used to articulate that quotation expression (as a quotation expression).

We cannot quote out loud a quotation of an italicized vehicle. And we cannot quote in writing a quotation of a sound. That is,

If we quote a vehicle $X$ with a quotation expression $Q$, it follows from SDS that $\mathrm{Q}$ must contain $\mathrm{X}$. But if $\mathrm{Y}$ is a vehicle that articulates $\mathrm{Q}$, then $\mathrm{Y}$ must include X.

These expressions dictate that they only can be articulated in distinct ways. This means infinitely many linguistic expressions can't be written, while another infinity can't be spoken; and so on. 


\section{THE HERESY OF PARAPHRASE RECONSIDERED}

Differences between expressions and their articulations have not always been respected in the literature. Davidson identifies expressions with phonetic and graphemic shapes (Davidson 1979, 90). ${ }^{4}$ A peculiar consequence of this identification is that it conflates the media themselves. If the word 'red' is identical to the graphemic and the phonetic shape used in articulating it, then the shapes themselves are identical. Clearly, something's gone wrong. The mistake is a failure to distinguish expressions from their vehicles of articulation. Likewise, the New Critics and other proponents of the Heresy of Paraphrase who wax philosophical about paraphrase and translation of poetry, have failed to distinguish expressions from their vehicles of articulation. Respecting the distinction reveals what is misguided about the Simple Refutation of the Heresy of Paraphrase.

The Simple Refutation is surely right-we can always introduce a new expression to mean exactly whatever an old expressions means-but if poems contain a meta-linguistic component that enables us to refer to their own articulation, then substituting synonyms will not achieve an adequate paraphrase or translation. These require not only synonyms but also identical articulations. Only repetition ensures this end! This follows from the disquotational nature of metalinguistic discourse. But then endorsing the Heresy of Paraphrase does not require rejecting semantic innocence: Linguistic expressions mean whatever they mean wherever they occur, but if the poem is partly constituted by its own articulation then it is not re-articulable in another medium. In poetry (just like quotation) the medium really is the message.

A quotation expression that quotes a vehicle is articulable only via that vehicle, and so too, a poem that is partly about its own articulation resists paraphrase or translation into any other idiom. Any such re-articulation changes the topic. In Brooks's own words:

The experience which he the poet 'communicates' is itself created by the organization of the symbols which he uses. The total poem is therefore the communication, and indistinguishable from it. $(1939,59)$

In Urban's words:

The artist does not first intuit his object and then find the appropriate medium. It is rather in and through his medium that he intuits his object.

The poet ... does well ... to keep to his own symbolic form. For precisely in that symbolic form an aspect of reality is given which cannot be adequately expressed otherwise. (Brooks 1939, quoting Urban, 262)

However, contra the New Critics, nothing follows about the language of poetry being distinct from the languages of other discourses; they are identical. The words in Cummings's poem mean exactly what they do in prose. His expression "clay

4. Indeed, this seems to be the received view. See Hawthorne and Lepore. 
pigeons" applies to clay pigeons, and so on. His grammar is the same. 'he' is the subject of 'he was a handsome man.' But because the poem is a device for presenting its own articulation, any effort to re-articulate (gjendikte) Cummings while ignoring his versification must fail. Ditto for Poe's "Bells" with its alliteration. It cannot be reproduced in another idiom if it is partly about its alliteration. Using other articulations will change its topic.

We can now understand why critics wonder whether Cummings's "Buffalo Bill" (a poem he composed for the typewriter, and indeed authoritative editions of his works go so far as to reproduce the typewriter look of his poems) can be rendered vocally. How do we reproduce in voice the visual, typewriter-spacing effects above? Critics wonder whether the belief that the poem can be spoken isn't illusory. Their concerns are legitimate. ${ }^{5}$ Maybe this is what Sartre had in mind when he said the poet "considers words as things and not as signs." Likewise, Dylan Thomas wrote about his first experiences with poetry that:

The first poems I knew were nursery rhymes, and before I could read them for myself I had come to love just the words of them, the words alone. What the words stood for, symbolised, or meant was of very secondary importance-what mattered was the very sound of them as I heard them for the first time on the lips of the remote and quite incomprehensible grown-ups who seemed, for some reason, to be living in my world.

He should be saying he was concerned not with the words of a poem, but with their articulations, especially with their sounds-a perceptible property. We can begin to understand the 'meaningfulness' of a poem like Lewis Carroll's Jabberwocky.

'Twas brillig, and the slithy toves

Did gyre and gimble in the wabe;

All mimsy were the borogoves,

And the mome raths outgrabe.

Translation of this poem is ill-conceived - if by 'translation' one means preservation of meaning, but not because its words mean something different inside and outside the poem (they are meaningless!).

\section{FIRST CONCLUSION}

The Heresy of Paraphrase says nothing more interesting about poetry than that (14) (construed as a true identity) cannot be said out loud.

\section{4. 'Madrid' F 'Madrid'}

5. Poems, unlike paintings, admit of many tokenings. What must be invariant throughout various tokenings of a poem in order for it to be the same poem tokened on each occasion? Given the systems of articulation we happen to employ it matters little if we write the poem in distinct fonts of different sizes in different colors, or on different sorts of surfaces-we might project it on a screen — so that its token is produced by rays of light—or its token might be a series of shadows. Though doing any of these might have a dramatic effect, that's not the same as a change in articulation. What needs to be settled is what the limits of change are for re-articulation. It may turn out much of what passes as Word Art, for example, is exactly that—art, and not poetry. 


\section{HYPERINTENSIONALITY}

According to the Heresy of Paraphrase thesis, poems can create what philosophers called hyper intensional linguistic environments; these are linguistic environments in which replacing an expression with its synonym changes meaning. The only uncontroversial occurrence of hyperintensionality in natural language is quotation. (15) is true though (16) is false.

15. 'bachelor' is the first word in 'bachelors are unmarried men.'

16. 'unmarried man' is the first word in 'bachelors are unmarried men.'

On these bases, no one concludes that quotation is not semantically innocent. Likewise, try replacing 'sheen' with 'luster' in Coleridge's poem The Rime of the Ancient Mariner (1797):
And through the drifts the snowy clifts
Did send a dismal sheen;
Nor shapes of men nor beasts we ken
The ice was all between.

The change sufficiently alters the rhythm and rhyme to break the bind between its lines, and thereby, alters the poem itself. Since synonym substitution in a poem can change meter or rhyme, etc., and thereby change the topic, poems too create hyper intensional contexts. The right conclusion is not that expressions carry unique meanings inside and outside of poems. Nothing so radical is required.

\section{SECOND CONCLUSION}

The data in support of the Heresy of Paraphrase can be explained by appeal to mechanisms already required to explain other sorts of hyper intensionality. Poetry, like quotation, doesn't support substitution of synonyms because it harbors devices for being literally (partly) about their own articulations. ${ }^{6}$ Since the vehicle/

6. Vendler observed that though you can know "poems, jokes, foreign words, tongue twisters, and the like" (Vendler 1972, 101), they cannot be believed. Why not? His reason is 'obvious,' he says:

Poems . . . cannot be reproduced in that-clauses; consequently there is no way of connecting them with 'believe.' Nothing prevents them from being known however. Knowing a poem, for instance, is knowing how it goes ... (Vendler 1972, 102)

What Vendler means is that we cannot make a poem the grammatical object of 'believes' or even 'says.' On this line of reasoning, we may also conclude that poems say nothing, since we cannot place the poem in the complement clause of 'says' to retrieve what it says. Cleanth Brooks concurs. In discussing whether poems say anything he wrote:

Let the reader try to formulate a proposition that will say what the poem 'says.' As his proposition approaches adequacy, he will find out, not only that he it has increased greatly the 
expression distinction is already available to us, no new radical claims about meaning differences of words inside and outside of poetry are needed.

\section{FINAL CONCLUSION}

Way more often than not the sounds or marks we make when we speak, write, type or word-process make little difference to the message we are trying to communicate. But sometimes we do care as much about certain aspects of the physical presentation of our articulation as we do about what that presentation expresses itself. Words express concepts; vehicles articulate words; and physical marks and sounds present vehicles. This tri-partite distinction, we have seen, is easy to run together, since each word requires an articulation and each articulation requires a sound, mark or another physical presentation.

When you reflect upon all the possibilities it's easy to see how what normally goes unnoticed can become the center of attention. Pause and examine these letters-their shapes are not unappealing. The sounds we make when we say these words out loud also exhibit fascinating features. The poet concurs. But, unlike ordinary folk, she wants to draw our attention to these articulations as much as to the ideas her words express. Instead of doing it with a scream or a whisper, in bold or colorful print, the poet invokes nonlinguistic devices to do so-for example, a rhyme schema. That 'bum' rhymes with 'gum' reveals nothing about their status as words. Sometimes rhymes or alliterations get created accidentally. When this happens a speaker might create an unintended association. To rectify these mishaps he might rearticulate his message, perhaps with a different pronunciation of the same words or with different words that convey the same content. In such circumstances, there is no intention for the discourse to be about those articulations. Poetry, however, is different. To grasp the poem requires a recognition that it's partly about its own articulation. In this regard, I come full circle and agree with Cleanth Brooks when counsels us "not to split the poem between its 'form' and its 'content'” (Brooks 1968, 201); and with Michael Urban when he concludes that in poetry, "form and content, or content and medium, are inseparable. The artist does not first intuit his object and then find the appropriate medium. It is rather in and through his medium that he intuits the object" (quoted in Brooks 1968, 199). And finally with Suzanne Langer (1942), who writes in her influential Philosophy in a New Key that "though the material of poetry is verbal, its import is not the literal

length, but that it has begun to fill itself up with reservations and qualifications-and most significant of all-the formulate will find that he has himself begun to fall back upon metaphors of his own in his attempt to indicate what the poem 'says.' In sum his proposition, as it approaches adequacy, ceases to be a proposition (181).

I of course deny anything so radical follows from these data; positing the poem's capacity to discuss its own articulations accommodates these data just as well. 
assertion made in the words but the way the assertion is made and this involves the sound, the tempo ... and the unifying all-embracing artifice of rhythm."7

\section{REFERENCES}

Almansi, Guido, and Merry, Bruce. 1977. Eugenio Montale: The Private Language of Poetry. Edinburgh: University of Edinburgh Press.

Barwise, J., and Perry, J. 1981. "Semantic Innocence and Uncompromising Situations". Midwest Studies in Philosophy 6(1): 387-404.

Brooks, Cleanth. 1939. Modern Poetry and the Tradition. Chapel Hill: University of North Carolina Press.

. 1968. The Well-Wrought Urn. London: Dennis Dobson.

Buhl, F. 1974. The Shorter Encyclopaedia of Islam, ed. H.A.R. Gibb and J.H. Kramers. Ithaca, NY: Cornell University.

Cappelen, E., and Lepore, E. 2004. Insensitive Semantics. Oxford: Basil Blackwell Publishers.

- 2007. Language Turned on Itself. Oxford: Oxford University Press.

Cook, M. 2000. The Koran: A Very Short Introduction. Oxford: Oxford University Press.

Davidson, Donald. 1965. "Theories of Meaning and Learnable Languages." In Proceedings of the 1964 International Congress for Logic Methodology and Philosophy of Science, ed. Y. BarHillel. Amsterdam: North Holland. Reprinted in Donald Davidson, Inquiries into Truth and Interpretation (Oxford: Oxford University Press, 1980), 3-16.

— 1968. "On Saying That." Synthese, 19, reprinted in Davidson, Inquiries into Truth and Interpretation (Oxford: Oxford University Press, 1984), 79-82.

- 1979. "Quotation." In Inquiries into Truth and Interpretation. (Oxford: Oxford University Press), 79-92.

Eliot, T.S. 1972. "Tradition and the Individual Talent.” In 20th Century Literary Criticism: A Reader, ed. David, Lodge. London: Longmans, 1972.

Fodor, J., and Lepore, E. 2001. The Compositionality Papers. Oxford: Oxford University Press.

Fodor, J., and Pylyshyn, Z. 1988. "Connectionism and Cognitive Architecture." Cognition 28: $3-71$.

Frege, G. 1892. "On Sinn and Bedeutung." In The Frege Reader, ed. M. Beaney. Oxford: Blackwell Press, 1997, 151-71.

—. 1918. “The Thought.” In The Frege Reader, ed. M. Beaney. Oxford: Blackwell Press, 1997, $325-45$.

Hawthorne, J., and Lepore, E. 2008. "On Words." Unpublished manuscript.

Higginbotham, James. 1986. "Linguistic Theory and Davidson's Program in Semantics." In Truth and Interpretation, ed. Ernie Lepore. Oxford: Basil Blackwell, 29-48.

Katz, Jerold. 1977. Semantic Theory. New York: Harper and Row.

Langer, Suzanne K. 1942. Philosophy in a New Key. Cambridge, MA: Harvard University Press.

Searle, John. 1968. Speech Acts. Cambridge: Cambridge University Press.

Vendler, Zeno. 1972. Res Cognitans. Ithaca, NY: Cornell University Press.

7. Earlier drafts of this paper have been presented at University of Florida, SUNY at Stony Brook, University of Oslo, University College Dublin, Simon Fraser University/University of British Columbia, University of Missouri at Columbia, St. Louis University, University of Mexico, École Normale Supérieure, Normal University of Bejiing, University of Western Michigan, University of California-Santa Cruz, University of California-Davis, and Northwestern University. I'd like to thank the audiences of each for all their helpful input. I'd like to thank in particular Jim Higginbotham, Anna Christina Ribeiro and Dan Sperber for their comments and encouragement. 